\title{
The Use of Hook Plate and Direct Coracoclavicular Ligament Repair in Acromioclavicular Joint Dislocation: Short-Term Result
}

\author{
Mohamed El-Sadek MD ${ }^{1 *}$, Emad Abd-Elhady MD $^{2}$ \\ ${ }^{1}$ Assistant Professor, Orthopedic Surgery Department, Zagazig University, Egypt \\ ${ }^{2}$ Assistant Professor, Orthopedic Surgery Department, Zagazig University, Egypt
}

*Corresponding Author: Mohamed El-Sadek MD, Assistant Professor, Orthopedic Surgery Department, Zagazig University, Egypt.

\begin{abstract}
Background: Acromioclavicular (AC) joint separation/dislocation represents widely recognized as shoulder injuries seen in general orthopedic. The recent biomechanical study of the AC joint made a lot of changes in the Treatment modalities of the joint.

Objective: our aim is to report the clinical outcome of management of acute acromioclavicular (AC) joint dislocation type III and V by clavicular hook plate with direct coracoclavicular ligament repair.

Patients and Method: A prospective study including thirty Four patients with AC joint dislocation type III and V Rockwood classification was conducted from June 2014 to October 2018 in our University Hospitals. Patients were treated by open reduction of the dislocated AC joint and internal fixation by clavicular hook plate together with direct repair of the coracoclavicular $(C C)$ ligament. Three patients lost during follow up and operation one patient died during follow up from cardiac problem before the surgery. The patients were evaluated by plain radiography for AC joint stability and functionally by Constant-Murley Score.
\end{abstract}

Results: Thirty patients with 22 patients (73.3\%) were male and eight patients $(24.7 \%)$ were female. The mean follow-up period was $24 \pm 4.3$ months (range 18-32 months). The mean age was $30 \pm 4.5$ years (range 2043 years). The operative time of our procedure was of a mean of $42 \pm 2.4$ minutes (range 34-59). All the patients had the plate removed after the third month postoperatively the mean 102 \pm 3.4 days (range 89-125). Follow-up radiograph after plate removal showed maintained reduction of AC joint in 28 patients. In the other two patients, loss of reduction of 1-2mm was noticed. The mean Constant-Murley score in the last follow-up was $93 \pm 5.6$ (range $85-99$ ).

Conclusion: A good functional outcome and low complication rate was reported with the used our approach in comparison with other operative procedures.

Keywords: Acromioclavicular dislocations, conoid ligament, trapezoid ligament, hook plate.

\section{INTRODUCTION}

Acromioclavicular (AC) joint dislocation is one of the common shoulder injuries noticed in general orthopedic practices. Management of $\mathrm{AC}$ joint injuries has been questionable and keeps on advancing (1). Treatment methods have changed with expanding comprehension of the idea of the issue and the biomechanics of the joint (2).

Various medical procedures have been delineated for the treatment of complete AC joint separation; anyway no understanding exists on the perfect treatment. The purpose of each kind of strategy is to balance out the clavicle by replacement of the burst coracoclavicular ligaments (3). The use of hook plates is a successful method For AC joint dislocation to improve shoulder capacity and license early gathering of the shoulder (4). Our target of this study is to assess the result of surgical treatment of acute AC dislocations (types III and V) (5) direct repair of ruptured $\mathrm{CC}$ ligaments and fixation by a hook plate and screws to maintain the AC joint stable even after removal of the plate.

\section{Patients and Methods}

A prospective study including thirty four patients had AC joint dislocation type III and V was conducted from June 2014 to October 2018 in our University Hospitals. All patients signed an informative consent form. Twenty two were males $(73.3 \%)$ and eight were females $(24.7 \%)$ with the mean age was $30 \pm 4.5$ years (rang20-43 years). Twenty two cases (73.3) were 
Rockwood type III and the other eight cases (26.7\%) were Rockwood type V dislocation. Nineteen cases $(63.3 \%)$ were right sided and eleven cases $(36.7 \%)$ were left sided. The mechanisms of injury included fifteen patients (50\%) after road traffic accidents (RTA), five patients $(16.7 \%)$ after falling, and ten patients (33.3\%) with sports injuries (Tab.1).

The preoperative evaluation of AC joint injury was done by plain $\mathrm{x}$-rays to classify the dislocation according to the degree of displacement. Exclusion criteria of our study was other types of AC dislocation (Rockwood types I, II, IV, and VI), open injuries, and patients with associated shoulder fractures. General anesthesia with the patient in the Beach chair position were used and freely mobility of the arm on the affected side. A sand bag was placed under the affected shoulder.

A "strap" incision starting 2-3 cm medial and posterior to the $\mathrm{AC}$ joint toward the tip of the coracoid process. Then exposure of deltoid and trapezius aponeuroses, AC joint, and the lateral one third of the clavicle. Then incision of the fascia, periosteum, and capsules for exposure of the dislocated joint and lateral third of the clavicle. Infra-clavicular dissection was done to identify the CC ligament. Stay sutures were applied to suspend the ligament using nonabsorbable polyester sutures and debridement of the $\mathrm{AC}$ joint and repair of the $\mathrm{AC}$ joint ligaments before application of the hook plate and temporary fixation of the reduced AC joint done by k-wire. (Figure: 1)

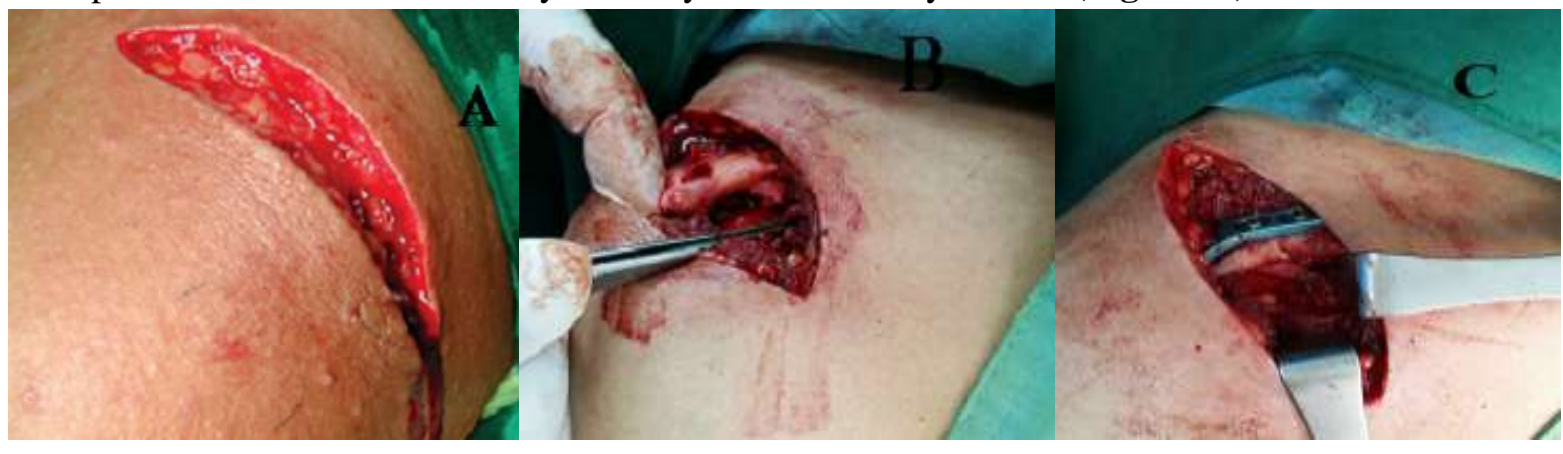

Fig.1. A: strap incision, B: rupture $A C$ and CC ligaments, $\boldsymbol{C}$ : repaired $A C$ ligament and fixation with hook plate

After securing the hook below the acromion and adjusted. Fixation of the plate to the clavicle with screws and the k-wire removed. We used locked stainless steel hook plates. The stay sutures are tightened to repair the coracoclavicular ligament with appropriate tension in the reduced position of the AC joint. Closure of the wound was done in layers, and pouch arm sling was used for the patient arm. Postoperative $\mathrm{x}$-ray was done, and the patient was discharged in the pouch arm sling. (Figure: 2, A\&B)
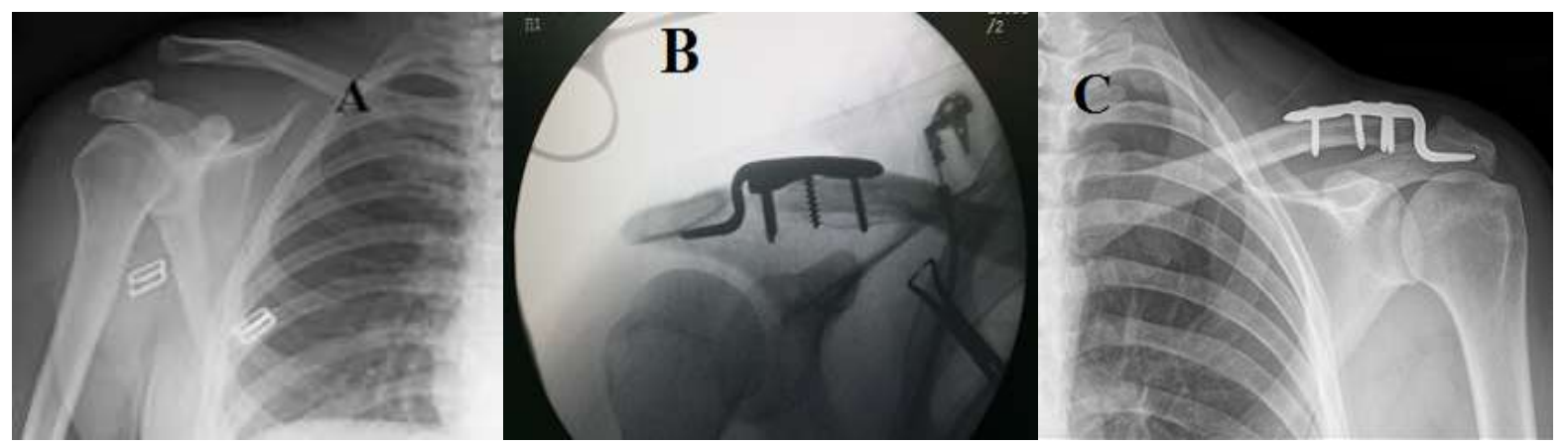

Fig.2. A: preoperative $x$-ray, B: intraoperative c-arm x-ray, $\boldsymbol{C}$ : post-operative $x$-ray

The follow-up was started 2 weeks postoperative for removal of sutures and starting range of motion with physiotherapist supervision after two weeks from surgery. The patient was instructed to avoid carrying heavy weight for the first 3 months by the affected limb. Monthly radiography was done till the third month postoperatively and removal of the plate and screws after 3 months. (Figure: 2, C)
After removal of the plate and screws the follow up radiography was done every three months for the first year and then every six months till the end of follow up period. Final functional evaluation was done according to Constant-Murley score (6) (Figure: 3, A) (Table1). 


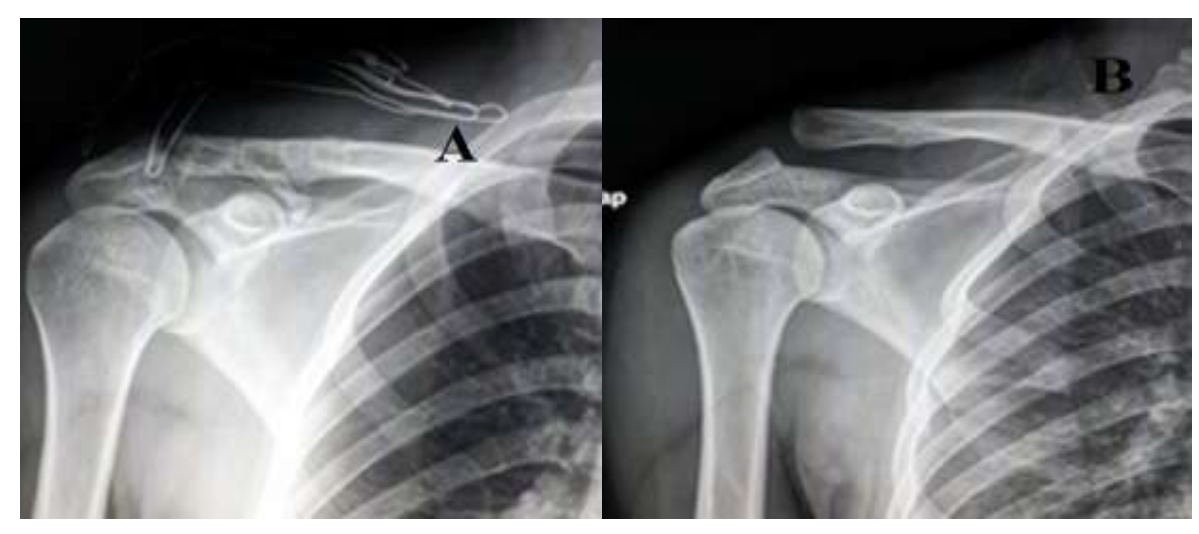

Fig.3. A: $x$-ray after plate removal and $\boldsymbol{B}$ : last follow up x-ray with minimal displacement of AC joint

\section{Results}

The patients mean age of was $30 \pm 4.5$ years (range 20-43 years). Eight patients had associated injuries either surgical or orthopedic injuries owing to high-energy trauma. Patients who had fractures in the same limb were excluded from the study. The mean time passed since the date of injury till operation was of $2 \pm 1.4$ days (range 1-5 days). The delay before the procedure was due to either late presentation or time for stabilization of the patient general condition. The mean operative time $42 \pm 2.4$ minutes (range $34-59 \mathrm{~min}$ ) calculated from the incision time till the end of the operation. One patient had superficial wound infection with discharge for more than 5 days as the patient was diabetic and over-weight. This infection was controlled with antibiotics and frequent dressing. The hospitalization period was of a mean $3 \pm 4.1$ days ranged 1-8 days. The patients with isolated AC injury had the shorter stay at hospital. Polytrauma patients and high-energy trauma patients had longer hospitalization stay for stabilization.
The active range of motion of the affected shoulder started two weeks after the operation. Six patients complained of mild impingement symptoms or shoulder discomfort during motion in the first 3 months. These symptoms disappeared after plate removal. Radiological assessment before plate removal showed no acromion osteolysis or loss of reduction. All the patients had the plate removed after third month postoperatively. The mean of the duration was 102.6 days (range 89-125 days).

The reduction of $\mathrm{AC}$ joint was maintained during the Follow-up in twenty eight patients. Slight loss of reduction of $2-4 \mathrm{~mm}$ of the AC joint was noticed in the other two patients that did not affect the final functional outcome. (Figure: 3, B)

The functional outcome of the patients was assessed using the Constant-Murley score (5). The final result of mean Constant-Murley Score was 93 \pm 5.6 (range 99-85). The mean follow-up period was $24 \pm 4.3$ months (range $18-32$ months) (Tab.1).

Table1. Demographic\& clinical characteristic of the studied patients (No=30)

\begin{tabular}{|c|c|c|c|}
\hline & & MEAN & RANGE \\
\hline \multicolumn{2}{|c|}{ Age } & $30 \pm 4.5$ & $20-43$ \\
\hline \multicolumn{2}{|c|}{ Operative Time } & $42 \pm 2.4$ & $34-59$ \\
\hline \multicolumn{2}{|c|}{ plate removal } & $102 \pm 3.4$ & $89-125$ \\
\hline \multicolumn{2}{|c|}{ Constant-Murley score } & $93 \pm 5.6$ & $85-99$ \\
\hline \multirow{2}{*}{\multicolumn{2}{|c|}{ Follow Up }} & $24 \pm 4.3$ & $18-32$ \\
\hline & & $\mathrm{NO}$ & $\%$ \\
\hline \multirow{2}{*}{ SEX } & MALE & 22 & $73.30 \%$ \\
\hline & FEMALE & 8 & $24.70 \%$ \\
\hline \multirow[b]{2}{*}{ SIDE } & RIGHT & 19 & $63.30 \%$ \\
\hline & LEFT & 11 & $36.70 \%$ \\
\hline \multirow{2}{*}{ INJURY TYPE } & III & 22 & $73.30 \%$ \\
\hline & $\mathrm{V}$ & 8 & $26.70 \%$ \\
\hline \multirow{3}{*}{ TRAUMA } & RTA & 15 & $50 \%$ \\
\hline & SPORT & 10 & $33.30 \%$ \\
\hline & FALLING & 5 & $16.70 \%$ \\
\hline
\end{tabular}


The Use of Hook Plate and Direct Coracoclavicular Ligament Repair in Acromioclavicular Joint Dislocation: Short-Term Result

Twenty two patients with type III injury 16 $(72.7 \%)$ and $6(27.3)$ and $15(68.2 \%)$ were right side affected and 6(27.3\%) were left side affected. There mean age $30 \pm 2.3$ with the range
20-401. The mean operative time $41 \pm 2.4$ with the range 35-59, The Constant Murley Score was $92 \pm 3.2$ with the range $85-99$, and The mean follow up 25 2.3 with range 18-32 (Tab.2).

Table2. Demographic\& clinical characteristic of patients with type III (no=22)

\begin{tabular}{|c|c|c|c|}
\hline & & MEAN & RANGE \\
\hline \multicolumn{2}{|c|}{ Age } & $30 \pm 2.3$ & $20-41$ \\
\hline \multicolumn{2}{|c|}{ Operative Time } & $41 \pm 2.4$ & $35-59$ \\
\hline \multicolumn{2}{|c|}{ Constant-Murley score } & $92 \pm 3.2$ & $85-99$ \\
\hline \multicolumn{2}{|c|}{ Removal of plate } & $102 \pm 4.3$ & $95-125$ \\
\hline \multicolumn{2}{|c|}{ Follow Up } & $25 \pm 2.3$ & $18-32$ \\
\hline & & $\mathrm{NO}$ & $\%$ \\
\hline \multirow{2}{*}{ SEX } & MALE & 16 & $72.70 \%$ \\
\hline & FEMALE & 6 & $27.30 \%$ \\
\hline \multirow[b]{2}{*}{ SIDE } & RIGHT & 15 & $68.20 \%$ \\
\hline & LEFT & 7 & $31.80 \%$ \\
\hline \multirow{3}{*}{ TRAUMA } & RTA & 11 & $50 \%$ \\
\hline & SPORT & 6 & $27.30 \%$ \\
\hline & FALLING & 5 & $22.70 \%$ \\
\hline
\end{tabular}

Eight patients were type V injury 6 (75\%) were right side affected and two $(25 \%)$ were left side affected. There mean age $31 \pm 4.2$ with the range $20-43$, the mean operative time $42 \pm 3.7$ with the range $34-55$, the mean time for plate removal

Table3. Demographic \& clinical characteristic of patients with type $V(n o=8)$

\begin{tabular}{|c|c|c|c|}
\hline & & MEAN & RANGE \\
\hline \multicolumn{2}{|c|}{ Age } & $31 \pm 4.2$ & $20-43$ \\
\hline \multicolumn{2}{|c|}{ Operative Time } & $42 \pm 3.7$ & $34-55$ \\
\hline \multicolumn{2}{|c|}{ Constant-Murley score } & $94 \pm 4.2$ & $90-98$ \\
\hline \multicolumn{2}{|c|}{ Removal of plate } & $103 \pm 1.3$ & $89-114$ \\
\hline \multirow{2}{*}{\multicolumn{2}{|c|}{ Follow Up }} & $23 \pm 2.3$ & $18-30$ \\
\hline & & NO & $\%$ \\
\hline \multirow{2}{*}{ SEX } & MALE & 6 & $75.00 \%$ \\
\hline & FEMALE & 2 & $25.00 \%$ \\
\hline \multirow[b]{2}{*}{ SIDE } & RIGHT & 4 & $50.00 \%$ \\
\hline & LEFT & 4 & $50.00 \%$ \\
\hline \multirow{3}{*}{ TRAUMA } & RTA & 4 & $50 \%$ \\
\hline & SPORT & 4 & $50.00 \%$ \\
\hline & FALLING & 0 & $0.00 \%$ \\
\hline
\end{tabular}

\section{DISCUSSION}

According to the type of injury to the AC joint capsule and ligaments as well as to the $\mathrm{CC}$ ligaments, $\mathrm{AC}$ joint dislocation can be classified as type I through type VI according to the severity (6). The significance of the CC ligaments and $\mathrm{AC}$ ligaments in controlling prevalent and level of interpretations has been clarified (6-9). Failure to surgically repair the conoid, trapezoid, and AC ligament function in treatment of $\mathrm{AC}$ joint dislocation may clarify the watched frequency of recurrent instability and distress (10).

The management of $\mathrm{AC}$ joint injuries by repair of the coracoclavicular and $\mathrm{AC}$ ligaments without the additional of any type of internal
$103 \pm 1.3$ with the range $89-114$ and the Constant Murley Score $94 \pm 4.2$ with the range 90-98 and the mean follow up period $23 \pm 2.3$ with the range 18-30 (tab.3). fixation is going to fail (3). A different types of internal fixation techniques was used, each has limitations and complications (11). These incorporate bandages, tension band wiring, and fixation of the AC joint with pins, fixation with washer and screw and clavicular hook plate and modified Weaver-Dunn procedure,(12).

The clavicular hook plate is an easy to handle rigid plate that aligns the $\mathrm{AC}$ joint and does not integrate with its rotational movement (13). The plate also allows early mobilization of the shoulder joint (4). Eschler et al. (14) in there comparative study between the hook plate and polydioxansulfate sling in the treatment of $\mathrm{AC}$ joint dislocation, concluded that hook plate fixation finally restores the coracoclavicular distance more accurately. 
In spite of the fact that there have been good outcomes in numerous investigations utilizing the hook plate, a few recorded complication as, infection, subacromial impingement, and acromial osteolysis have been accounted for $(15,16)$. Along these lines, it is critical to illuminate the patients about the need regarding convenient evacuation of the plates as prescribed to constrain the bleakness related with the plate being left without removal (12).

Also, it has been accounted for that when the plate has been applied alone in primary cases, even one year after plate removal, there is the chance of recurrence in $12 \%$ of cases (17). For that, we think the essential stabilizers of the AC joint, particularly the CC ligaments, ought to be tended to when managing intense $\mathrm{AC}$ dislocation. The use of grafts or synthetic materials for coracoclavicular fixation has been related with numerous complications. A few authors announced erosion of the distal clavicle and infection brought about by the synthetic loop (18).

Injury of the neurovascular can occur as a result of passing the sutures around the base of the coracoid process (19). Costic et al. (20) in their study using semitendinosus tendon for anatomical reconstruction of $\mathrm{CC}$ ligament compared with intact CC ligament. Although the reconstruction resulted in a significant increasing in biomechanical terms, properties of strength of up to $40 \%$ of the normal CC ligament and maximum resistance of up to $75 \%$ were shown.

In a cadaveric study of anatomic reconstruction, Lee et al. (21) also showed impairment of the graft internal integrity and coracoid layer fractures to be the reason for failure in studies of anatomic reconstruction with semitendinosus graft.

In our study, we used the hook plate with repair of CC ligament for management of types III and $\mathrm{V}$ of $\mathrm{AC}$ joint dislocation. It is an easy and rapid procedure that allows reduction and maintains the reduction of the joint and allows early active motion of the shoulder joint and early physiotherapy. CC ligament is dissected and repaired again to restore the normal anatomical restraint against AC joint subluxation. The hook plate is removed after third month postoperatively. This period allowed good healing of the $\mathrm{CC}$ ligament and the $\mathrm{AC}$ ligaments and avoided the development of complications.
The shoulder function was significantly improved after the hook plate was removed. And how to further optimize the design of hook plate and what is the optimal time to remove the hook plate in order to decrease the incidence of complications are the focus for future studies.

There have been reports showing that complications could occur postoperatively. Lin et al demonstrated by musculoskeletal sonography that clavicular hook plate could cause subacromial shoulder impingement and rotator cuff lesion. Their data also suggest an association between hardware-induced impingement and poorer functional scores. They advocated the removal of the implant as soon as bony union and/or ligamentous healing is achieved [10].

The mean follow-up was $24 \pm 4.3$ months (range 18-32 months). Patients in the current study had neither persistent impingement symptoms nor acromial osteolysis. The Constant-Murley shoulder outcome score was of a mean of $93 \pm 5.6$ (range 85-99) at the last follow-up. It is a better functional outcome than one group of patients who underwent hook plate and ligament reconstruction by Palmaris longus (88.5) and another group used suture anchors (92.7) in a comparative study done by An et al. (22) This score also is better than the score of patients who underwent modified Weaver-Dunn procedure and hook plate in treatment of $\mathrm{AC}$ joint dislocation (88.2) by Liu et al. (3).Our data provide short term results for this technique. long-term results are needed to confirm these preliminary findings and more investigation needed.

\section{CONCLUSiON}

The use the clavicular hook plate combined with CC ligament repair yields good short-term clinical results with a good functional outcome and very low complication rate in the management of AC dislocation type III and V.

\section{REFERENCES}

[1] Talbert TW, Green JR III, Mukherjee DP, Ogden AL, Mayeux RH. Bioabsorbable screw fixation in coracoclavicular ligament reconstruction. J Long Term Eff Med Implants 2003; 13:319-323.

[2] Kiefer H, Claes L, Burri C, Holzwarth J. The stabilizing effect of various implants on the torn acromioclavicular joint. A biomechanical study. Arch Orthop Trauma Surg 1986; 106:42-46.

[3] Liu H, Chou Y, Chen C, Chia W, Wong C. Surgical treatment of acute acromioclavicular 
joint injuries using a modified Weaver-Dunn procedure and clavicular hook plate. Orthopedics 2010; 33. doi:10.3928/0147744720100625-10. Pub Med.

[4] Amarasekera S, Davey KJ. Clavicle hook plateis it the definitive intervention? A retrospective analysis of clavicle hook plate fixation. J Bone Joint Surg 2006; 88:315.

[5] Rockwood CAJr, Williams GR, Young DC. Disorders of the acromioclavicular joint. In Rockwood CA, Malsen FA, eds. The shoulder. 2nd ed. Philadelphia, PA: WB Saunders Co.; 1998. 483-553

[6] Constant,C.R,\&Murley,A.H. A clinical method of functional assessment of the shoulder. Clinical Orthopaedics\&Related Research, 1987,214, 160-164.

[7] Debski RE, Parsons IMIV, Woo SL, Fu FH. Effect of capsular injury on acromioclavicular joint mechanics. J Bone Joint Surg Am 2001; 83:1344-1351.

[8] Fukuda K, Craig EV, An KN, Cofield RH, Chao EY. Biomechanical study of the ligamentous system of the acromioclavicular joint. J Bone Joint SurgAm 1986; 68:434-440.

[9] Jari R, Costic RS, Rodosky MW, Debski RE. Biomechanical function of surgical procedures for acromioclavicular joint dislocation. Arthroscopy 2004; 20:237-245.

[10] Mazzocca AD, Santangelo SA, Johnson ST, Rios CG, Dumonski ML, Arciero RA. Abiomechanical evaluation of an anatomical coracoclavicular ligament reconstruction. Am J Sports Med 2006; 34:236-246.

[11] Guttmann D, Paksima NE, Zuckerman JD. Complications of treatment of complete acromioclavicular joint dislocations. Instr Course Lect 2000; 49:407-413.

[12] Jafary D, KeihanShokouh H, Najd Mazhar F, Shariat Zadeh H, Mochtary T. Clinical and radiological results of fixation of acromioclavicular joint dislocation by hook plates retained for more than five months. Trauma Monthly 2014; 19:e13728.

[13] Tiren D, van Bemmel AJM, Swank DJ, van der Linden FM. Hook plate fixation of acute displaced lateral clavicle fractures: mid-term results and a brief literature overview. J Orthop Surg Res 2012; 7:2
[14] Eschler A, Gradl G, Gierer P, Mittlmeier T, Beck M. Hook plate fixation for acromioclavicular joint separations restores coracoclavicular distance more accurately than PDS augmentation, however presents with a high rate of acromial osteolysis. Orthop Trauma Surg 2012; 132:33-39.

[15] Nadarajah R, Mahaluxmivala J, Amin A, Goodier DW. Clavicular hookplate: complications of retaining the implant. Injury 2005; 36:681-683.

[16] Chandrasenan J, Badhe S, Cresswell T, Beer J. The clavicular hook plate: consequences in three cases. Eur J Trauma Emerg Surg 2007; 33:557-559.

[17] Di Francesco A, Zoccali C, Colafarina O, Pizzoferrato R, Flamini S. The use of hook plate in type III and $\mathrm{V}$ acromio-clavicular Rockwood dislocations: clinical and radiological midterm results and MRI evaluation in 42 patients. Injury 2012; 43:147152.

[18] Neault MA, Nuber GW, Marymont JV. Infections after surgical repair of acromioclavicular separations with nonabsorbable tape or suture. J Shoulder Elbow Surg 1996; 5:477-478.

[19] Pavlik A, Csépai D, Hidas P. Surgical treatment of chronic acromioclavicular joint dislocation by modified Weaver-Dunn procedure. Knee Surg Sports TraumatolArthrosc 2001; 9:307312.

[20] Costic RS, Labriola JE, Rodosky MW, Debski RE. Biomechanical rationale for development of anatomical reconstructions of coracoclavicular ligaments after complete acromioclavicular joint dislocations. Am J Sports Med 2004; 32:1929-1936.

[21] Lee SJ, Nicholas SJ, Akizuki KH, McHugh MP, Kremenic IJ, Ben-Avi S. Reconstruction of the coracoclavicular ligaments with tendon grafts: a comparative biomechanical study. Am J Sports Med 2003; 31:648-655.

[22] An WJ, Sun JB, Ye P, Guo WW. Comparative study on the treatment of acromioclavicular joint dislocation: coracoclavicular ligament reconstruction combined with hook plate fixation or suture-anchor fixation. ZhonghuaWaiKe Za Zhi 2013; 51:349-353.

Citation: Mohamed El-Sadek MD, Emad Abd-Elhady MD. The Use of Hook Plate and Direct Coracoclavicular Ligament Repair in Acromioclavicular Joint Dislocation: Short-Term Result. ARC Journal of Orthopedics. 2020; 5(2):8-13. DOI: https://doi.org/10.20431/2456-0588.0502002.

Copyright: () 2020 Authors. This is an open-access article distributed under the terms of the Creative Commons Attribution License, which permits unrestricted use, distribution, and reproduction in any medium, provided the original author and source are credited. 